\title{
Helen May, Baljit Kaur, and Larry Prochner Empire, Education, and Indigenous Childhoods: Nineteenth Century Missionary Infant Schools in Three British Colonies
}

Farnham, U.K.: Ashgate Studies in Childhood, 1700 to the present, 2014, 278 pp.

\section{Katie Pickles}

University of Canterbury

During the past two decades a transnational approach to the history of the former British Empire has gained momentum. This book is a part of that quest to look beyond national boundaries, and, as a result, to reach greater understanding. Researching and writing transnational history is difficult: the amount of knowledge required and the time needed to gather data can be overwhelming. A common response is for edited collections to gather together scholars working on similar topics but in different places - the result being that the opportunity for comparison is limited.

This contribution to the transnational history of education is an exemplary study that benefits from the collaboration of three scholars as collective authors and two more as foreword writers. The collective approach enables a complex and insightful examination of places where the British Empire was a shared experience, but where diverse local contexts existed.

The time period covered is the 1820-50s. The places under examination are missionary settlements across the northern part of the North Island of New Zealand, Upper Canada, and British-controlled India. The authors focus on uncovering, comparing and contrasting infant schools at these sites. The last twenty years has seen the emergence of a large body of work on the British missionary enterprise, and with a specialised focus on the history of education, this volume both draws upon and contributes to that literature. The volume asserts that "by revealing some patterns of the tapestry of engagement between missionaries and Indigenous peoples in the early nineteenth century, with infant schools in the foreground, the intention is, from 
the 'history lessons' learned, to reframe our understandings of the consequences for children, their peoples, and cultures" (20).

Sarah de Leeuw and Margo Greenwood provide a rich and extensive foreword that draws out the significance of the book, and places it in a theoretical context. Themselves experts on the history of race, indigeneity and education, de Leeuw and Greenwood emphasise the work of Michael Foucault, Ann Laura Stoler, Edward Said, and Linda Tuhiwai Smith. They suggest that an important lesson from the book is that "colonial education was a constantly adapting, and in many cases a hybridized and often somewhat haphazard, project" (xxii).

Building upon the foreword, the introduction strongly sets the context and injects further depth into the book. Aptly titled "Old World Enlightenment: New World Contexts," the introduction argues that infant schools were established during the 1820-40s in Britain for children between the ages of two and seven years from the poor and working classes who had demonstrated "the possibilities of moral reform realized through a curricular mix of physical movement, sensory activity, music and entertainment, the three Rs and biblical missives" (1). In all three sites, the authors argue that transplantation of Britain's infant schools was done with the intention of speeding-up the conversion of Indigenous peoples by missionaries to Christianity and to European modes of civilisation. The solid underlying presence of Enlightenment thinking is highlighted.

Chapter 1 covers missionary educational and evangelical endeavours across the three sites of study. The dominant argument is that the geographically dispersed places shared a common missionary objective grounded in Enlightenment thinking. Chapter 2 then sets the British context, where the infant schools originated. These "nurseries of discipline" (71) were carefully thought-out and monitored by those who sought societal reform. With a thorough induction into missionary enterprises and infant schools in Britain, the book changes tack to proceed through three case study chapters. Chapter 3 concerns British India; Chapter 4 is about Canadian infant schools; and Chapter 5 is about New Zealand. The case studies are meticulously researched. The maps and illustrations here and throughout the book are extremely well-chosen and useful.

The conclusion champions transnational approaches and the importance of indigenous agency. It does not shy away from relating historical experiences to the present day. In harmony with the overall tone of the book, the conclusions are openminded and open-ended, calling for more research and more questioning. Indeed, contradictions of attempting to improve children, but within an imperial context, surface throughout the book. While the infant schools were literally "enlightened" during their time, the suggestion is that the majority world is still treated in similar ways today, instead of a focus on indigenous agency and autonomy.

Overall, this is a complex, intensively research, and extensively grounded book. Little-known episodes from the past are etched out and an exploratory, non-judgemental framework is used for analysis. There are occasional strong and direct arguments contained within the pages, but they appear to be dampened down for two reasons: first, true collaborative research often involves compromise and balance; and 
second, in casting a wide net, transnational history errs towards moderate conclusions. Previous nation-based studies arose in reaction to the homogenous, celebratory imperial perspectives that came before them. A transnational framework such as employed in this book, combines both the imperial and national standpoints, highlights historical Enlightenment thinking, and is content to complexify the past through solid and thorough research. 